\title{
Bivocalidade científico-poética em uma seleção de poemas de Arnaldo Antunes
}

\author{
Sandra Mina Takakura \\ Universidade do Estado do Pará (UEPA), Belém, Pará, Brasil \\ sandramita@hotmail.com
}

DOI: http://dx.doi.org/10.21165/el.v46i1.1538

\begin{abstract}
Resumo
Arnaldo Antunes é conhecido por combinar as criações lexicais com recursos gráficos e sonoros, explorando uma linguagem verbi-voco-visual em termos de James Joyce. A poesia concreta, gênero discursivo escolhido pelo autor, transcende os limites das forças criadoras descritas por Bakhtin como a centrípeta, encontrada no poema, e a centrífuga, observada nos campos discursivos e no heterodiscurso do romance, o que permite problematizar a linguagem criativa do poeta que acessa discursos do campo científico por meio de uma arte discursivamente responsiva. Esse artigo tem como objetivos estudar a expressividade em uma seleção de poemas, mapeando os neologismos semânticos sintagmáticos resultantes de uma nova motivação e uso em novos contextos, aliada à noção de signo ideológico e escrutinar discursos relativos aos campos ideológicos, levando em conta a linguagem verbovocovisual.
\end{abstract}

Palavras-chave: heterodiscurso; Arnaldo Antunes; Bakhtin; Volochínov; Guilbert.

\section{Scientific-poetical bivocalism in a selection of poems, by Arnaldo Antunes}

\begin{abstract}
Arnaldo Antunes is known for combining lexical creations with vocal and graphic resources exploring through a kind of verbi-voco-visual language in James Joyce's terms. The concrete poetry, the discursive genre selected by the author, exceed the limits of the creative forces drawn by Bakhtin as the centripetal force found in the poem and the centrifugal force observed in discursive fields, and the heteroglossia found in the novel, which allows problematizing the poet's creative language that accesses the scientific field by a discursively responsive art. This article has as objectives studying the expressiveness in a selection of poems, by mapping the semantic and syntagmatic neologisms resulted from a new motivation and the use in new contexts, allied with the notion of ideological signs, as well as scrutinizing the discourses related to the ideological fields, by taking into account the verbi-voco-visual language.
\end{abstract}

Keywords: heteroglossia; Arnaldo Antunes; Bakhtin; Voloshnov; Guilbert.

\section{Introdução}

Na obra Teoria do romance I: A estilística (2015), Mikhail M. Bakhtin contrasta o gênero romanesco prosaico e a poesia de forma polarizada, partindo do fato de que o estudo da poética do cenário de 1930, na Rússia, não privilegiava uma abordagem que aprofundasse a complexidade da construção da prosa romanesca, uma vez que servia somente aos propósitos dos estudos da poesia. Para Bakhtin (2015), o estudo da prosa deveria escrutinar o heterodiscurso, traçado por ele para investigar tanto as intenções discursivas das personagens quanto as do autor refratadas na obra. Embora a poesia estivesse relacionada diretamente às intenções do autor, mantendo uma relação de 
proximidade com a obra, a bivocalidade presente nela exercia somente um papel acessório em seu conjunto, se comparado ao encontrado na prosa romanesca. Um estudo poético, de acordo com o teórico, portanto, mantinha o foco no "problema do símbolo poético" e na questão da polissemia, partindo da premissa de que a linguagem fosse considerada una e estável sem que fossem apontadas as inúmeras ramificações das variantes sociais, estas que se fariam notar no heterodiscurso da prosa romanesca (BAKHTIN, 2015, p. 120).

No entanto, na década de 1950, em um momento de intensas experimentações no campo artístico e literário, houve o surgimento da poesia concreta que, de acordo com Haroldo de Campos (1977, p. 44), transcendeu os contornos da "poesia" e da "prosa", superando o entendimento acerca da literatura como um projeto meramente estético, descompromissado das questões sociais, partindo para um projeto literário crítico, levando em conta as problemáticas da sociedade moderna.

O processo criativo da poesia concreta evidenciava a ressignificação de signos, resultado de processos de criações neológicas, e escolhas das opções lexicais e sintáticas do autor, aliada às experimentações na linguagem visual e gráfica. A poesia concreta recorre na atualidade em obras como a de Arnaldo Antunes, cuja produção poética é notadamente permeada por criações neológicas e experimentações nas linguagens visuais.

Medviédev (2010, p. 199) assevera que os modos de representação estão intrinsecamente relacionados com as possibilidades de representação disponíveis a determinadas épocas por meio de gêneros discursivos: "o domínio da época em seus diferentes aspectos - familiar e cotidiano; social e psicológico - acontece em uma ligação ininterrupta com os meios de sua representação, isto é, com as principais possibilidades de construção de gênero".

O gênero discursivo pode ser descrito como uma combinação do uso da língua, escolhas do autor em determinadas esferas comunicativas: "elementos (conteúdo temático, estilo e construção composicional)", estas que se unem "no todo do enunciado" em "uma esfera de comunicação" (BAKHTIN, 2011, p. 279). A pesquisadora bakhtiniana Luciane de Paula (2016) chama a atenção a dois aspectos no gênero discursivo, o aspecto autoral, das marcas estilísticas de um autor, e o aspecto geral comum a gênero discursivo tipificado ${ }^{1}$.

Para este estudo, foram selecionados o título da coletânea 2 ou + corpos no mesmo espaço, o poema que dá nome à coletânea, "Terra" e "Átomo Indivisível" a serem investigados enquanto enunciados artísticos responsivos ao discurso da esfera científica, por meio da noção de heterodiscurso vicejada por Mikhail M. Bakhtin, partindo da seleção das criações neológicas semânticas, seguindo as noções de Louis Guilbert nos corpora de análise. Como procedimento metodológico, foram coletados os neologismos literários que se configuram como resultados das escolhas do autor, ou seja, os neologismos estilísticos (GUILBERT, 1972, p. 24-25), observados à luz de noções de signo ideológico e conteúdo semiótico traçados por Volochínov e Bakhtin em

\footnotetext{
1 “Análise Dialógica de Discursos Transmedia", palestra proferida no $64^{\circ}$ Seminário do GEL (Grupo de Estudos Linguísticos do Estado de São Paulo), realizado na Universidade Estadual Paulista (UNESP), campus de Assis/SP, de 06 a 08 de julho de 2016.
} 
Marxismo e Filosofia da Linguagem, levando em conta a linguagem em seus aspectos verbovocovisuais.

Arnaldo Antunes, por meio de sua arte, estabelece relações dialógicas, desestabilizando o discurso científico. Consequentemente, desafia as categorizações e os limites das distinções das esferas ideológicas artísticas e científicas, possibilitando transcendê-los, subvertendo, dessa forma, a autonomia do campo científico, no qual o conteúdo subordina a forma, no território do campo artístico em que o estilo predomina sobre o conteúdo. Trata-se, portanto, de um estudo acerca do discurso enquanto refração de grau segundo do discurso científico, evidenciada por Grillo (2006), que parte do método formal de Medviédev (2010).

\section{A forma e o tema da poesia concreta}

Os gêneros ou subgêneros literários podem ser vistos como gênero discursivo bakhtiniano dotados de forma e tema que se inter-relacionam, produzidos a partir das intenções comunicativas imersas em determinados contextos sócio-históricos. Portanto, a poesia concreta é vista como um gênero discursivo relacionado à vida política, social e econômica, em uma determinada sociedade:

As relações de produção e a estrutura sociopolítica que delas diretamente deriva determinam todos os contatos verbais possíveis entre indivíduos, todas as formas e os meios de comunicação verbal: no trabalho, na vida política, na criação ideológica. Por sua vez, das condições, formas e tipos da comunicação verbal derivam tanto as formas como os temas dos atos de fala. (VOLOCHÍNOV; BAKHTIN, 2012, p. 43).

Por "atos de fala", Volochínov e Bakhtin (2012, p. 286) denotam gêneros discursivos realizados em sua forma concreta, dotados de materialidade, ${ }^{2}$ que são inerentes ao uso concreto da língua em uma determinada época e local, sendo consideradas "formas relativamente estáveis e normativas de enunciado".

É importante frisar que a poesia concreta foi criada em torno de 1950 pelo trabalho do grupo "Noigandres" em São Paulo e do poeta suíço Eugen Gomringer, em meio a intensas reflexões quanto às formas e às linguagens literárias que motivaram experimentações visuais e sonoras, observadas nas experimentações tipográficas e espaços em branco na página em "um lance de dados" de Stéphane Mallarmé, notado no caligrama do poeta Apollinaire "Comme si", aliada às "reduções linguísticas" da poesia pau-brasil, no falar regional e no cinema de montagem soviética de Eisenstein (CAMPOS, 1977). A linguagem verbal estabeleceu relações com outras mídias, autoproclamando-se como uma arte "espaço temporal" e, em termos joyceanos, "verbivoco-visual" (CAMPOS, 1977, p. 45-46).

Similar a outros movimentos modernos, a poesia concreta tornou-se uma forma de enunciado estável disponível aos autores de fases posteriores, havendo poucas restrições quanto às escolhas de temas a serem abordados, permitindo uma liberdade maior de criação.

\footnotetext{
2 Anotações da disciplina: "Por uma Ciência Dialógica da Linguagem: Discurso, Enunciado e Relações Dialógicas", ministrada pela Profa. Dra. Sheyla Grillo, de 15 a 19 de fevereiro de 2016.
} 
O processo das escolhas composicionais perpassa a consciência ideológica do autor imersa no contexto histórico e social, no qual o signo ideológico é constituído enquanto possuidor de um tema compartilhado socialmente e que, ao final, recebe um acento individual, representado a "cada manifestação verbal" (VOLOCHÍNOV; BAKHTIN, 2012, p. 46).

Os temas abordados, por meio das experimentações na linguagem verbal e nas criações estilísticas, podem ser compreendidos como dotados igualmente de sentidos ideológicos. Tais escolhas, conhecidas como o estilo do autor, são escrutinados por meio da estilística e resultam em sua expressividade (IGNEZ; CARDOSO, 2012).

\section{Produto ideológico}

O poema concreto é composto pela linguagem verbal e não verbal, que podem refletir ou refratar a realidade e o posicionamento do autor e sua relação com a música e a arte gráfica e visual, portanto, podem ser considerados produtos ideológicos:

Um produto ideológico faz parte de uma realidade (natural ou social) como todo corpo físico, instrumento de produção ou produto de consumo; mas, ao contrário destes, ele também reflete e refrata uma outra realidade, que lhe é exterior. Tudo que é ideológico possui um significado e remete a algo situado fora de si mesmo. (VOLOCHÍNOV; BAKHTIN, 2012, p. 31).

A respeito do signo, "tudo que é ideológico é um signo" - asseveram Volochínov e Bakhtin (2012, p. 31), o que indica que o signo seja um produto ideológico por excelência, cuja abrangência ideológica remete ao semiótico que transcende para além dele: "Tudo o que é ideológico possui um valor semiótico" (BAKHTIN, 2012, p. 33). Tais valores podem ser compreendidos no domínio do "campo" discursivo distinto, como o artístico e o científico abordados neste estudo (VOLOCHÍNOV; BAKHTIN, 2012, p. 33).

A compreensão dos poemas concretos por parte do leitor é dificultada pelos recursos gráficos inerentes ao gênero, que podem impossibilitar a oralização. Alguns dos poemas são oralizados pelo próprio autor no $\mathrm{CD}$ que acompanha o livro. Compreende-se que a oralização não seja "[...] uma simples passagem da palavra escrita para a falada" (PIGNATARI, 2005, p. 59), há uma realização semiótica e estilística em sua declamação.

No corpus de extração são estabelecidas relações de intermidialidade posto que se observa a combinação de "pelo menos duas mídias convencionalmente distintas ou, mais exatamente, duas formas midiáticas de articulação", uma vez que a experimentação linguística alia a visualidade e em alguns poemas a oralização em estúdio por meio de arranjo sonoro (RAJEWSKY, 2012, p. 24). Para Pignatari (2005, p. 10), o poeta [concreto] trabalha o signo verbal", presente em todas as manifestações artísticas e culturais e linguagens, sem se restringir à modalidade escrita ou oral da língua, o que remete à noção de signo ideológico, cujas escolhas são frutos tanto da escolha estilística do autor, quanto da intencionalidade comunicativa que engendram a expressividade no poema. 


\section{Forças criativas na língua}

Bakhtin (2015, p. 39) parte do contraste entre as forças criadoras que atuam sobre a língua: a força centrípeta constituindo: "as forças da unificação e centralização do mundo verboideológico" da língua nacional e una que mantém uma impressão de unidade e de estabilidade. A força centrífuga da língua, por sua vez, é "estratificada em camadas não só de dialetos no exato sentido do termo [...], mas também [...] em linguagens socioideológicas" (BAKHTIN, 2015, p. 41), de vários grupos heterogêneos, em linguagem da literatura, e ameaça desestabilizar a unidade da língua nacional através do heterodiscurso.

As forças centrípetas asseguram a compreensão mútua dos falantes, sendo a "língua idelogicamente preenchida". Essa abarca a visão de mundo e o posicionamento de inúmeras áreas da "vida ideológica", ainda que denote uma visão de língua abstrata (BAKHTIN, 2015, p. 40). Por outro lado, as forças centrífugas representam a "descentralização e separação", enriquecendo a linguagem por meio da estratificação heterodiscursiva de linguagens socialmente heterogêneas, da visão de enunciados responsivos a enunciados anteriores, e no trato da linguagem do outro (BAKHTIN, 2015, p. 42).

É importante salientar que as "forças criadoras" estão presentes na força centrípeta da língua nacional por meio do conjunto de normas gramaticais padronizantes, das quais novas formas lexicais podem vir a surgir (BAKHTIN, 2015, p. 40). No entanto, a criação lexical também é operada pelas vias das forças centrífugas, por meio dos usos concretos das variantes de diversos grupos, em variados campos discursivos, como o religioso, jornalístico, o científico e o artístico (BAKHTIN, 2015).

Para Bakhtin (2015), a língua abstrata manipulada pelas vias da força centrípeta no processo criativo do poema pode apresentar certa bivocalidade não central, uma vez que as construções dos temas focam nos símbolos e nas polissemias, resultado das combinações das unidades lexicais em plano sintagmático. A linguagem concreta, por outro lado, pode ser encontrada no gênero da prosa romanesca, que explora as interações do cotidiano e suas variantes linguísticas sociais, geracionais, econômicas etc. À vista disso, as forças criadoras atuariam em gêneros discursivos distintos da poesia e da prosa romanesca.

A obra de Arnaldo Antunes acaba por quebrar essa distinção, visto que a escolha do gênero discursivo poesia concreta permite o acesso às criações tanto por meio da via das forças centrífugas, como das forças centrípetas, sendo possível realizar um estudo acerca do heterodiscurso nos poemas escolhidos.

\section{Conteúdo ideológico e neologismo}

$\mathrm{Na}$ poesia concreta, há intensa experimentação linguística, resultando em novas lexias que, nesse estudo, são vistas como signos ideológicos. Há duas formas de se conceber o neologismo lexical: por meio das regras de formação concatenadas e não concatenadas, presentes na gramática nas quais atuam as forças centrípetas e aos signos já existentes são atribuídos novos sentidos, ou por meio de novas colocações e combinações dos signos. Os primeiros são os neologismos formais e os segundos são 
considerados, por Louis Guilbert (1972, p. 22, tradução nossa), criações neológicas semânticas:

[...] a neologia semântica é aquela que se opera através da mudança do grupamento de semas correspondente a um lexema, segundo as modalidades diversas. São aquelas que foram descritas pelos retóricos sob o nome de sinédoque, metáfora, comparação, metonímia [...]. O que devemos lembrar nessas mudanças de sentidos é que eles permanecem não-aparentes no quadro de lexemas, e que aqueles não são expressos pela inserção da palavra na frase, por uma distribuição nova na possível composição do sintagma e da frase. ${ }^{3}$

A formação da neologia semântica, os semas das lexias podem sofrer modificações, bastando que estes sejam combinados a "determinantes" (déterminants) apontados por Guilbert (1972, p. 22, tradução nossa). O processo não se restringe ao campo semântico, mas adentra o campo sintático, portanto, é considerado também uma "neologia sintagmática" (néologie syntagmatique).

O processo de formação neológica semântica pode ser operado: "Com a passagem de um termo de um vocabulário especializado para outro vocabulário especializado, o peso de uma significação que não provém somente do referente novo, mas também do meio profissional dos falantes." (sociologique) (GUILBERT, 1972, p. 22, tradução nossa). Por conseguinte, pode-se afirmar que o signo ideológico relacionado à esfera científica, uma vez inserido no contexto da esfera artística, passa pelo processo neológico semântico, sintáticosintagmático, resultando em um signo que congrega certa bivocalidade associada ao seu uso na primeira esfera e ao novo uso e acentuação na segunda esfera discursiva, em um processo sociológico e, portanto, heterodiscursivo.

Os neologismos quando partem da necessidade comunicativa, como a exemplo o caso de avanços tecnológicos na sociedade moderna e "o ato de nomear todas as invenções científicas e técnicas" - como aponta Guilbert (1972, p. 24-25, tradução nossa $)^{5}$, são considerados denominativos. Ou, ainda, quando são fruto "da busca da expressividade para traduzir os pensamentos antigos de uma nova maneira ou para dar nome aos modos de pensar ou de sentir inéditos" (GUILBERT, 1972, p. 24-25, tradução nossa) são considerados conotativos ou estilísticos.

O neologismo na esfera científica, que acessa principalmente o referente, cristaliza-se pelo uso, podendo ser incorporado ao acervo lexical de uma dada língua.

\footnotetext{
${ }^{3}$ « [...] néologie sémantique est celle qui s'opère dans le changement du groupement des sèmes afférents à un lexeme, selon des modalités diverses. Celles-ci ont été décrites par les rhétoriciens sous le nom de synecdoque, métaphore, comparaison, métonymie.[...]. Ce qu'il faut retenir de ces mutations de sens, c'est qu'elles demeurent non-apparentes dans le cadre du lexeme, aussi longtemps qu'elles ne sont pas manifestées par l'insertion du mot dans la phrase, par une distribution nouvelle des composants possibles du syntagme et de la phrase. ».

${ }^{4}$ «Aussi le passage d'un terme d'un vocabulaire spécialisé à un autre vocabulaire spécialisé le charge d'une signification nouvelle qui ne provient pas seulement du réfèrent nouveau mais aussi du milieu professionnel des locuteurs. ».

${ }^{5}$ « la dénomination de toutes les inventions scientifiques et techniques »; «l'expressivité pour traduire des pensers anciens d'une manière nouvelle ou pour donner leur nom à des modes de penser ou de sentir inédits ».
} 
Por outro lado, a criação lexical na esfera literária é pautada na expressividade que não se restringe somente ao referente, mas à intenção criativa do autor, sendo, portanto, dificilmente incorporada ao dicionário de uma língua:

A expressão literária constitui um nível particular da língua, que se opõe a outros níveis. Nela a fantasia verbal para a criação é mais livre. Embora seja possível, é mais difícil uma criação poética vir a fazer parte do léxico da língua. Continuará sendo, na maioria das vezes, uma lexia virtual que se presta àquele momento específico, àquela obra específica, àquele autor específico. (CARDOSO, 2004, p. 159).

Consumando uma necessidade expressiva, por meio de um estilo e um modo de falar acerca do referente, o neologismo literário relaciona o autor e os leitores que podem assumir os papéis de enunciador e enunciatários. Tal fato converge à noção de Barbosa (1981, p. 81) acerca da criação neológica ser possível somente "no curso do processo discursivo, no circuito de uma comunicação que faz surgir simultaneamente a presença de dois interlocutores e o papel ideológico da linguagem.”.

A forma de apreensão do novo signo, resultante dos processos neológicos, pode ser compreendida a partir da relação do novo signo ideológico com os outros já conhecidos, por meio de conexões de "natureza semiótica", ou ideológicas descritas por Volochínov/Bakhtin (2012, p. 34), posto que o signo só se torna signo em um "processo de interação entre uma consciência individual e uma outra" em um "processo de interação social" (p. 34), no qual se materializa o signo ideológico. Tal fato nos leva a afirmar que o processo de formação lexical, motivado pela expressividade estilística, não exclui a intenção comunicativa imbricada no seu processo de criação. Fato este reforçado pelo poema, no plano discursivo e enunciativo que, sendo uma ação responsiva a um discurso científico anterior, os leitores passam a ser interlocutores desse processo de interação verbal.

A leitura e a recepção da obra podem ser compreendidas como um processo de interação, no qual o locutor e o próprio autor criador interagem ativamente no processo de apreensão dos sentidos ideológicos dos signos.

\section{Heterodiscurso artístico-científico}

O título da coletânea 2 ou + corpos no mesmo espaço é um enunciado artístico responsivo ao discurso da esfera científica: "Dois corpos não ocupam o mesmo espaço". Tal premissa pode ser decorrente das Leis de Newton acerca da dinâmica dos movimentos, que discorre a respeito das forças contrárias que agem sobre a massa de um determinado corpo, podendo amparar o Princípio da Impenetrabilidade, discussão essa do campo da metafísica. Nesse ponto, a discussão científica intersecciona a discussão filosófica sobre os corpos e a matéria. A afirmação da impossibilidade de dois objetos ocuparem o mesmo espaço é superada precisamente na física quântica pelo conceito do quinto estado da matéria - o condensado de Bose-Einstein, no qual dois corpos seriam capazes de se interpenetrar, em tese, ocupando o mesmo espaço.

O poema é verbo-visual, composto com recurso gráfico de sobreposição de enunciados e de unidades lexicais, o que impossibilitaria a realização de sua leitura. $O$ processo de criação do título pode ser compreendido como neologismo sociológico em 
termos de Guilbert, quando termos passam de um campo discursivo a outro. Com a mudança no campo semântico, resulta o neologismo semântico, sintagmático, compreendido como: Uma nova forma de expressar uma ideia antiga da esfera científica, a de corpos celestes referidos simplesmente como corpos, e, portanto, "2 ou + corpos" poderia potencialmente indicar os corpos celestes que ocupam o mesmo espaço sideral, onde se encontram os planetas e todo o Sistema Solar.

Ou ainda, o recurso gráfico de sobreposições de enunciados denota a corporificação dos enunciados e dos signos ideológicos que compõem o poema, transmitindo uma ideia nova: corpos com sentido de objetos, pois a visualidade das palavras sobrepostas reforça a responsividade à máxima da Impenetrabilidade, expandindo para a noção de uma verdade superada, indicando a possibilidade de os corpos ocuparem o mesmo espaço, podendo se somar e formar um único corpo.

A representação gráfica do poema destaca as partes onde as unidades lexicais se sobrepõem umas às outras, permitindo que o leitor visualize a corporização de enunciados e signos ideológicos. Na capa, as partes sobrepostas possuem um destaque em cores diferentes, produzindo o resultado de soma de corpos, enquanto que o poema impresso em preto na folha de rosto interna possui as sobreposições destacadas em branco, implicando a anulação de corpos. Portanto, as sobreposições podem indicar tanto a soma quanto a subtração dos corpos.

O poema intitulado "2 ou + poemas no mesmo espaço" (ANTUNES, 1997, p. 24-25), ao contrário do efeito de sobreposição do título da coletânea ( 2 ou + corpos no mesmo espaço), explora os espaços brancos do papel, distribuindo as unidades lexicais em duas páginas, utilizando as lacunas entre as unidades lexicais. $O$ poema é oralizado pelo próprio autor/locutor em uma faixa de CD que acompanha o livro. Através do recurso de edição, o leitor/interlocutor possui acesso à realização oral do poema, ora ocorrendo a quebra na linearidade da linguagem, com a sobreposição de vozes por meio de edição e do recurso de eco, ora com longas pausas entre as lexias, remetendo às lacunas entre os elementos lexicais na página impressa. Tal realização permite combinação de sintagmas e novos sentidos como: "dois corpos", "ou no mesmo", "somam", "somam não se", "não multiplicam", "somem", remetendo às novas possiblidades no campo científico atual.

O poema "Terra" (ANTUNES, 1997, p. 40-41), disposto em duas páginas escuras, está impresso no lado esquerdo, "casulo azul guarda as asas da água", trazendo à direita a imagem do planeta Terra. A unidade lexical "casulo", sendo combinada com a determinante "azul", remete ao significante oculto e flutuante "borboleta azul", este enquanto produto há muito exportado pelo país, tornando-se praticamente o seu símbolo. No entanto, a imagem do planeta Terra expande a possibilidade interpretativa de "casulo azul", antes restrito ao país, ao próprio planeta e ao seu ecossistema como um todo.

Por meio do recurso da neologia semântica, "casulo" ganha o sentido de "planeta" e "simulacro da vida", um planeta que guarda a vida. Há uma circularidade no poema, na composição neológica "as asas da água", remetendo novamente à borboleta azul, ao planeta água, ao planeta Terra, uma vez que atribui "asas" a um composto mineral, sendo água abundante e geradora da vida no planeta. Tanto os determinantes "azul" quanto "água" funcionam como atributos do planeta, sendo usuais as 
combinações de "planeta azul" e "planeta água", o que leva à conclusão de que o neologismo comunica de uma nova maneira uma ideia antiga. Como resultado tem-se a bivocalidade no discurso da esfera artística que se relaciona de forma dialógica com o discurso da esfera científica.

O poema "Átomo divisível” (ANTUNES, 1997) é construído através das combinações das seguintes unidades lexicais: "Átomo divisível", "montanha móvel", "certeza volúvel", "mundo delével", "aço inoxidável”, portanto, a neologia semântica é resultante da seguinte fórmula: substantivo + determinante, apontando as verdades científicas superadas.

Até o século XV, o termo átomo denotava "cada uma das partículas minúsculas, eternas e indivisíveis que se combinam e desagregam, movidas por forças mecânicas da natureza, determinando, dessa maneira, as características de cada objeto". Sabe-se, atualmente, que o átomo é divisível em partículas menores, com a descoberta dos prótons positivos que, juntamente com os nêutrons, compõem o núcleo e dos elétrons negativos que transitam em torno do núcleo. Portanto, a definição atual deixa de lado o termo "partícula", preferindo o termo "sistema": "sistema energeticamente estável, eletricamente neutro, que consiste em um núcleo denso, positivamente carregado e envolvido por elétrons" (HOUAISS; VILLAR; FRANCO, 2009, p. 216). O sentido leva a uma verdade científica superada: "átomo divisível", sendo a negação de um enunciado acerca de uma verdade científica.

A montanha costumava ser obstáculo instransponível no passado, superado no processo de urbanização e planejamento de uma cidade, adequando-se às rodovias, sendo perfurada para que se construam túneis de acesso e ainda, devido à própria urbanização, sofre erosão e deslizamentos em sua encosta. Portanto, "montanha móvel" indica a perda da imobilidade, da estabilidade e da firmeza.

A combinação da unidade lexical "certeza" com o atributo não usual "volúvel" passa a conotar o sentido da problemática do mundo modernizado, no qual as verdades são negadas e superadas à medida que as pesquisas científicas avançam. A certeza na atualidade é temporalmente marcada, sendo que o signo recebe um novo conteúdo ideológico atrelado à questão temporal. Tal questão é reforçada pela combinação das unidades lexicais "mundo" e "delével"; este último conota o sentido daquilo que "pode ser apagado eliminado, destruído" (HOUAISS; VILLAR; FRANCO, 2009, p. 609).

O poema é oralizado somente em parte na faixa de $\mathrm{CD}$, juntamente com outros poemas. Este estudo levará em conta apenas a parte relacionada ao poema em questão. Os dois primeiros versos do poema são entoados como um mantra budista japonês, realizados em tom grave e prolongado, o que restringe e direciona o sentido das combinações lexicais que formam o poema. O recurso gráfico do poema impresso lembra uma imagem esférica distorcida que se estende por duas páginas, que lembra o cogumelo formado na explosão da bomba atômica. Anualmente, principalmente nas cidades de Hiroshima e Nagasaki, são celebrados rituais budistas para lembrar as vítimas da bomba, sendo também um ritual budista pela paz.

A última combinação, "aço inoxidável", conota um produto resultante do avanço científico que substituiu o ferro pela sua resistência e durabilidade na aplicação na indústria, nos carros, na construção civil, na medicina, etc. A característica desse 
produto contrasta com os aspectos da mutabilidade, da volatilidade e da instabilidade, consequências das combinações das unidades lexicais anteriores, apontando à permanência e durabilidade, resultantes dos avanços da ciência.

$\mathrm{O}$ autor escolheu novas formas de comunicar ideias já conhecidas pelo grande público, por meio de enunciados artísticos responsivos aos enunciados anteriores da esfera científica, que já foram suplantados por novos avanços conquistados por meio de pesquisas na área.

Nesse estudo, foram observadas as criações lexicais ideológicas no discurso artístico como refrações de grau segundo do discurso da esfera científica que levam o questionamento do autor/locutor à obra. Isso permite afirmar que o autor permanece próximo à sua obra enquanto locutor do discurso da esfera artística, rompendo, dessa forma, o modelo bakhtiniano das forças criadoras atuantes em uma língua, segundo as produções literárias distintas da poesia e da prosa. $\mathrm{O}$ autor/locutor reflete a sua visão de mundo, ao mesmo tempo em que refrata o discurso científico na obra.

\section{Considerações finais}

Nos objetos desta investigação agem tanto as forças centrípetas quanto as forças centrífugas de criação, sendo possível mapear os neologismos e os novos discursos em uma cadeia comunicativa de enunciados, que são ações responsivas aos discursos da esfera científica, configurando a bivocalidade e, portanto, a heterodiscursividade.

A noção de gênero discursivo permitiu que fosse realizado um estudo do poema concreto enquanto ato responsivo ao enunciado científico, congregando, no estilo do autor, a escolha do gênero discursivo, da linguagem e das combinações dos elementos lexicais, em novas formas de articular ideias antigas e/ou conhecidas, escrutinadas por meio da teoria de neologismos de Guilbert, Barbosa e Cardoso.

Foram observadas nos objetos escolhidos as relações discursivas entre os campos artístico e científico, por meio do estudo das criações neológicas, traçando seus conteúdos ideológicos e semióticos, no contexto da construção de gênero discursivo intermidiático que engloba as modalidades da escrita e congrega alguns aspectos da fala, como a oralidade e a semiótica referida nesse estudo como verbovocovisual. Concluiuse, dessa forma, que os objetos analisados podem ser considerados uma criação literária responsiva, bivocal e heterodiscursiva, nos quais os seguintes sentidos podem ser acessados: 
Quadro 1. Resultados de "2 ou + corpos"

\begin{tabular}{|l|l|}
\hline Verbo & Corpos - objetos, unidades lexicais, signos. \\
\hline Voco & $\begin{array}{l}\text { Sobreposição de unidades lexicais articuladas na faixa do CD - promovem a quebra na } \\
\text { linearidade da linguagem. } \\
\text { O recurso do eco e da pausa entre a articulação das palavras - apontam às desconexões das } \\
\text { unidades lexicais. }\end{array}$ \\
\hline Visual & $\begin{array}{l}\text { Soma/multiplicação - marcada pelas cores distintas no local nas sobreposições das } \\
\text { palavras impressas na capa colorida. } \\
\text { Some - marcada pelo vazio e espaços em branco nas sobreposições das palavras impressas } \\
\text { na capa interna. }\end{array}$ \\
\hline Sentido & $\begin{array}{l}\text { A impressão simboliza a corporização do enunciado artístico-científico, em que "corpo" no } \\
\text { poema indica objeto. } \\
\text { O poema é um ato responsivo aos discursos da área científica. }\end{array}$ \\
\hline
\end{tabular}

Quadro 2. Resultados de "Terra"

\begin{tabular}{|l|l|}
\hline Verbo & $\begin{array}{l}\text { Casulo azul/Asas da vida - o sentido leva à borboleta azul - produto de exportação } \\
\text { nacional - planeta água, planeta Terra, ecossistema. } \\
\text { A oralização é realizada pelo leitor. }\end{array}$ \\
\hline Visual & $\begin{array}{l}\text { Planeta - direciona o sentido dos enunciados verbais para o planeta Terra, ampliando o } \\
\text { sentido. A borboleta azul, em seu estado de casulo, pode ser uma metáfora ao planeta } \\
\text { Terra, que recebe outras nomeações como planeta água e planeta azul. }\end{array}$ \\
\hline Sentido & $\begin{array}{l}\text { A borboleta azul que apontava metonimicamente ao país se estende ao planeta Terra, } \\
\text { transcendendo os limites da nação. O planeta necessita de cuidados, pois é referido como o } \\
\text { grande casulo azul que guarda a vida. } \\
\text { A expressão poética é um ato responsivo ao discurso científico de preservação da vida e do } \\
\text { ecossistema. }\end{array}$ \\
\hline
\end{tabular}

Quadro 3. Resultados de "Átomo divisível"

\begin{tabular}{|l|l|}
\hline Verbo & $\begin{array}{l}\text { A fórmula seguinte constrói o poema: "substantivo + determinante" } \\
\text { Atomo divisível - indica que a ciência produz conhecimentos que são verdades } \\
\text { temporárias. } \\
\text { Montanha móvel - mostra que a ciência modifica o cenário, indica a mutabilidade. } \\
\text { Certeza volúvel - conota que a ciência continua a criar novas verdades. } \\
\text { Mundo delével - aponta que o mundo pode ser destrutível por meio da ciência. } \\
\text { Aço inoxidável - implica em afirmar que a ciência produz a permanência por meio de } \\
\text { suas pesquisas como a durabilidade do material. }\end{array}$ \\
\hline Voco & $\begin{array}{l}\text { Entoação do poema como um mantra budista japonês em tom grave, estabelece a } \\
\text { relação com o ritual rememorativo da ocasião da explosão das duas bombas atômicas } \\
\text { em solo japonês. }\end{array}$ \\
\hline Visual & $\begin{array}{l}\text { A disposição do poema impresso remete ao formato do cogumelo observado no ar na } \\
\text { ocasião das explosões das bombas atômicas. }\end{array}$ \\
\hline Sentido & $\begin{array}{l}\text { O átomo divisível remete às bombas atômicas, e, portanto, ao perigo da Ciência, ao } \\
\text { mesmo tempo em que aponta às mudanças no cenário geográfico, criações de novas } \\
\text { verdades, novas certezas. }\end{array}$ \\
\hline
\end{tabular}

Os quadros anteriores indicam que, para se acessar o sentido da obra de Arnaldo Antunes, necessita-se compreender as três dimensões que constituem a sua obra: verbovocovisual.

Pode-se ainda apontar, de acordo com o estudo realizado, que nas criações do autor as forças centrífugas e centrípetas agem de forma conjunta, agregando novos sentidos, ao mesmo tempo em que constroem uma bivocalidade discursiva no campo 
artístico de forma responsiva ao campo científico, ou seja, resultam em criações heterodiscursivas.

Há a necessidade de se realizar estudos em uma seleção maior de poemas, e explorar alguns aspectos que ficaram de fora deste estudo, como as criações neológicas morfológicas, como sendo formações de novos signos ideológicos, em um estudo acerca do estilo do autor, levando em conta a figura do autor criador e a figura pública, sempre tendo em vista o gênero discursivo enquanto um enunciado que envolve dois interlocutores sendo o endereçado o público-leitor.

\section{REFERÊNCIAS}

ANTUNES, A. 2 ou + corpos no mesmo espaço. São Paulo: Ed. Perspectiva, 1997.

BAKHTIN, M. M. Estética da criação verbal. Tradução de Paulo Bezerra. 4. ed. São Paulo: Martins Fontes, 2011. Teoria do romance I: A estilística. Rio de Janeiro: Editora 34, 2015 [1975]. BARBOSA, M. A. Léxico, produção e criatividade. São Paulo: Global editora, 1981. CAMPOS, H. de. Ruptura dos Gêneros na Literatura Latino-Americana. São Paulo: Ed. Perspectiva, 1977.

CAMPOS, A. de; PIGNATARI, D.; CAMPOS, H. Mallarmé. São Paulo: Perspectiva, 1991.

CARDOSO, E. A. A criação neológica estilística. Matraga, Rio de Janeiro, v. 16, p. 105-118, 2004.

CARDOSO, E. A.; CONDÉ, V. G.; GIL, B. D. (Org.). Modelos de análise linguística. São Paulo: Contexto, 2009.

GRILLO, S. V. de C. Esfera e Campo. In: BRAIT, B. (Org.). Bakhtin: outros conceitoschave. São Paulo: Contexto, 2006. p. 133-160.

Fundamentos bakhtinianos para a análise de enunciados verbo-visuais. Filologia linguística portuguesa, n. 14(2), p. 235-246, 2012.

GUILBERT, L. Théorie du néologisme: Communication de M. Louis Guilberï (ParisNanterre) au XXIVe Congrès de l'Association, le 24 juillet 1972.

HOUAISS, A.; VILlAR, M. de S.; FRANCO, F. M. de M. Dicionário Houaiss da lingua portuguesa. Rio de Janeiro: Objetiva, 2009.

IGNEZ, A. F.; CARDOSO, E. de A. Escolhas lexicais: estilo e expressividade. In: MICHELETTI, G. Estudos de discurso e estilo. São Paulo: Terracota, 2012. p. 17-38.

MEDVIÉDEV, P. N. O método formal nos estudos literários: Introdução crítica a uma poética sociológica. São Paulo: Ed. Contexto, 2010.

PIGNATARI, D. O que é comunicação poética. São Paulo: Ateliê Editorial, 2005. 
RAJEWSKY, I. O. Intermidialidade, intertextualidade e "remediação": Uma perspectiva literária sobre a intermidialidade. In: DINIZ, T. F. N. Intermidialidade e Estudos interartes: Desafios da arte contemporânea. Belo Horizonte: Ed. UFMG, 2012. p. 1545.

VOLOCHÍNOV, V. N.; BAKHTIN, M. M. Marxismo e filosofia da linguagem. Tradução de Michel Lahud e Yara Frateschi Vieira. São Paulo: Hucitec, 2012.

Recebido em: 13/08/2016

Aprovado em: 08/02/2017 